\title{
Nanofluids for Solar Thermal Collection and Energy Conversion
}

\author{
Mohammed Abdullah Hussain ${ }^{1}$, Sumith Yesudasan ${ }^{2 *}$ and Sibi Chacko ${ }^{1}$ \\ ${ }^{1}$ School of Engineering and Physical Sciences, Heriot-Watt University, Dubai, UAE \\ ${ }^{2}$ Department of Engineering Technology, Sam Houston State University, Huntsville, TX, USA
}

\begin{abstract}
Author emails:
Mohammed Abdullah Hussain: mah11@hw.ac.uk

"Sumith Yesudasan: sumith.yesudasan@shsu.edu

Sibi Chacko: c.sibi@hw.ac.uk
\end{abstract}

\begin{abstract}
This paper investigates the improvement in solar energy collection and conversion using $\mathrm{Al}_{2} \mathrm{O}_{3}-\mathrm{Water}$ nanofluids in a solar flat plate collector (SFPC). The efficiency of a solar flat plate collector using water as the fluid medium is analyzed experimentally and theoretically. For theoretical analysis, a mathematical model in MATLAB is used to simulate and is validated by the experimental results. To enhance the solar energy collection and conversion efficiency of the SFPC, $\mathrm{Al}_{2} \mathrm{O}_{3}$-Water nanofluid was selected as the fluid medium. The nanofluid properties like density, specific heat capacity, thermal conductivity and viscosity are analyzed and compared for several models of $\mathrm{Al}_{2} \mathrm{O}_{3}$-Water nanofluids and the best model was selected to modify the simulation. Effect of particle diameter in the nanofluid was found to be marginal on the nanofluid properties. The optimum volume concentration of the nanofluid was found to be $4 \%$ giving an efficiency increase of $7.78 \%$ in the SFPC over the use of water. This reduces the area of the SFPC by $10.5 \%$.
\end{abstract}

Keywords: Solar Flat Plate Collector, Efficiency, Nanofluid, Surfactant, $\mathrm{Al}_{2} \mathrm{O}_{3}$-Water, Ultrasonic agitation

\section{Introduction}

With diminishing sources of energy and an increase in $\mathrm{CO}_{2}$ emissions, causing global warming and other environmental impacts, the world is moving more towards renewable energy for daily energy needs as it is mostly clean and infinite. The sun's energy (solar energy) is the most abundant form of renewable energy available to us by nature. Keeping in mind that every form of energy available to us is derived from solar energy and it is the most utilized form of renewable energy. Although it is intermittent, it is available everywhere.

The best way to utilize energy is to use it in its original form rather than facing conversion losses. This can be accomplished by using solar collectors that use solar irradiation coming from the sun to produced thermal energy (heat) for hot water or air (space heating) applications [1]-[5]. It basically works as a heat exchanger with the sun as its main heat source. Solar flat plate collectors (SFPC's) are commonly used solar collectors due to its performance and easy maintenance. Solar flat plate collectors (SFPC's) are used mainly for household water and space heating. They are very economical and require no tracking since the optimum performance angle is usually towards the equator, facing south in the Northern Hemisphere and north in the Southern Hemisphere [6].

Common fluid mediums used in a SFPC are water, ethylene glycol and engine oil. Recent studies have shown that suspending nanosized particle $(1-100 \mathrm{~nm})$ in a base fluid can improve the properties of the fluid significantly, especially the thermal conductivity of the fluid depending on the particle material. These fluids are known as nanofluids. The term 'nanofluid' was initiated by Choi and Eastman [7]. Since the fluid properties are enhanced, an increase and efficiency can be obtained by simply replacing the fluid in the SFPC with the nanofluid which increases the heat transfer rate to the system.

Researchers in the last few years have investigated the effect of various nanofluids in SFPC's experimentally and theoretically. Several factors of the nanofluid like volume concentration, nanoparticle diameter and synthesizing methods have been investigated. Many theoretical and empirical models have also been derived from different researchers for the thermophysical properties of nanofluids such as density, specific heat capacity, thermal conductivity, and viscosity.

The main objective of this study is to integrate nanofluids in a solar flat plate collector (SFPC) thereby improving overall system performance. To investigate this, we 1) simulate and conduct experimental validation on the performance of a SFPC using water, 2) Analyze the properties of a nanofluid by studying different models derived empirically and theoretically, 3) Modify the simulation using nanofluids for an improved efficiency, 4) Investigate economic benefits of using a nanofluid, 5) Overcome nanofluid stability issues by using ultrasonication agitation, 6) Investigate experimental studies on using nanofluids in a SFPC's. 


\section{Components and working of a SFPC}
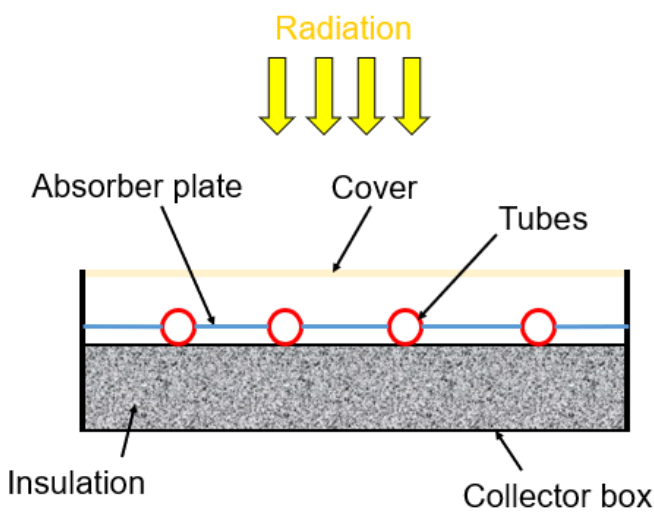

Figure 1 - Components of a solar flat plate collector

Solar radiation passes through the glass cover allowing the absorber plate to absorb the radiation. Tubes are part of the absorber plate such that when the fluid passes through the tubes, it absorbs the heat from the plate for the heat exchange to occur. This cycle is repeated.

The collector consists of the following components, as shown in Figure 1 and described below,

- Cover: Radiative transfer material to protect the system from dust and corrosion. Usually made of glass which allows solar transmission and reduces convection losses and radiation losses from the absorber plate by trapping the heat.

- Absorber plate: Flat plates to which the pipes are attached. Usually made of high thermal conductive materials like copper. The plate is coated with a high absorptance, low-emittance layer (usually black).

- Tubes: Fluid tubes attached to the absorber plate form a heat exchanger chamber through which the heat transfer fluid circulates. Tubes are connected at both ends by header tubes which are of larger diameter than the riser tubes.

- Insulation: Minimizes heat losses around the collector.

- Collector box: Metallic casing that surrounds the components and protects from dust, moisture etc.

\section{Theoretical equations of a SFPC}

Heat Loss through convection and radiation,

$\mathrm{Q}_{\mathrm{o}}=\mathrm{U}_{\mathrm{L}} \mathrm{A}_{\mathrm{c}}\left(\mathrm{T}_{\mathrm{c}}-\mathrm{T}_{\mathrm{a}}\right)$

Collector heat input,

$\mathrm{Q}_{\mathrm{i}}=\mathrm{I} \tau \alpha \mathrm{A}_{\mathrm{c}}$

Hence, the useful heat gain is the different between the heat input and the heat loss,

$Q_{u}=Q_{i}-Q_{o}=I \tau \alpha A-U_{L} A_{c}\left(T_{c}-T_{a}\right)$

Ideally, the useful heat gain is expressed as,

$\mathrm{Q}_{\mathrm{u}}=\dot{\mathrm{m}} \mathrm{c}_{\mathrm{p}}\left(\mathrm{T}_{\mathrm{o}}-\mathrm{T}_{\mathrm{i}}\right)$

The ratio of the ideal to real value gives the heat removal factor,

$F_{R}=\frac{Q_{u, \text { ideal }}}{Q_{u, \text { real }}}=\frac{\dot{m} c_{p}\left(T_{o}-T_{i}\right)}{A_{c}\left[I \tau \alpha-U_{L}\left(T_{c}-T_{a}\right)\right]}$

The final expression for the useful heat gain of the collector,

$\mathrm{Q}_{\mathrm{u}}=\mathrm{F}_{\mathrm{R}} \mathrm{A}_{\mathrm{c}}\left[\mathrm{I} \tau \alpha-\mathrm{U}_{\mathrm{L}}\left(\mathrm{T}_{\mathrm{c}}-\mathrm{T}_{\mathrm{a}}\right)\right]$

Hence, the thermal efficiency of the collector can be expressed as the ratio of the useful energy gain from the collector to the solar irradiation on the collector surface area,

$\eta=\frac{Q_{u}}{A_{c} I}$

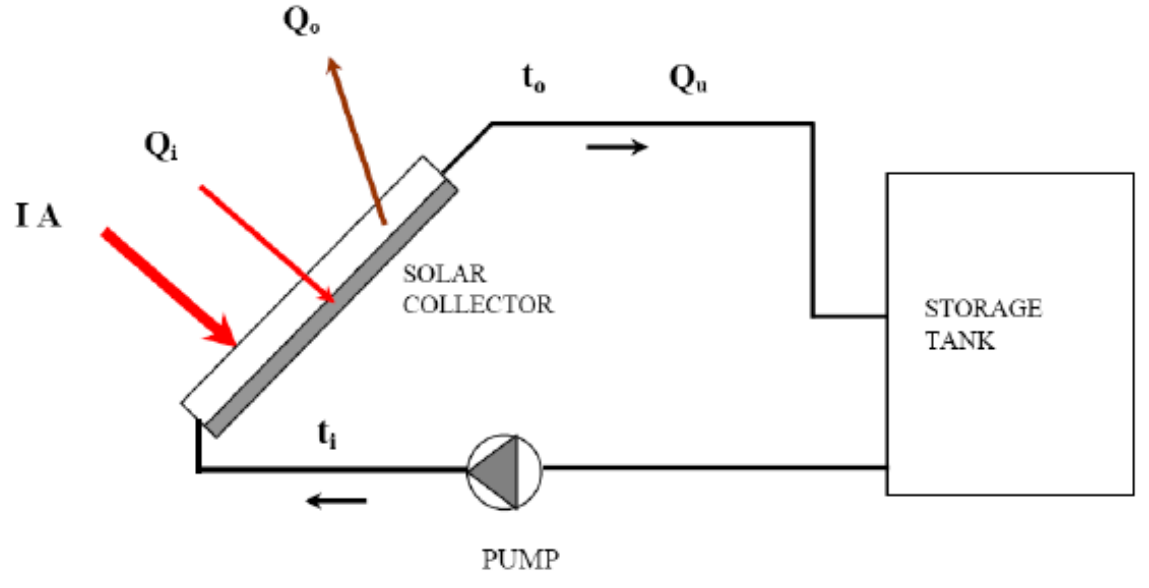

Figure 2 - Solar flat plate collector (SFPC) configuration [8] 


\section{Experimentation of SFPC using water}

\section{Experimental setup}

An experiment was conducted to analyze the performance of a SFPC. The experimental setup is as shown in Figure 3.

The experimental setup consists of the following components,

- SFPC - AES SUPREMACY COLLECTOR 1.5AR $\left(\right.$ Area $\left.=1.3 \mathrm{~m} \mathrm{x} 1.15 \mathrm{~m}=1.5 \mathrm{~m}^{2}\right)$

- Water tank

- Pipes connections and valves
- Pressure relief (P.R) valve

- Pump - To adjust flow rate

- Filter - Filters water to the tank

- Thermocouples - Measures the temperature at inlet and outlet of the SFPC $\left({ }^{\circ} \mathrm{C}\right)$

- Flow meter - Measures the flow rate $(\mathrm{kg} / \mathrm{s})$

- Pyranometer - Measures the solar irradiation $\left(\mathrm{W} / \mathrm{m}^{2}\right)$

The data from the experiment was logged using a cDAQ Assistant Hardware from National Instruments (NI) for LabVIEW 2019. The block diagram formulated in LabVIEW 2019 is as shown in Figure 4.

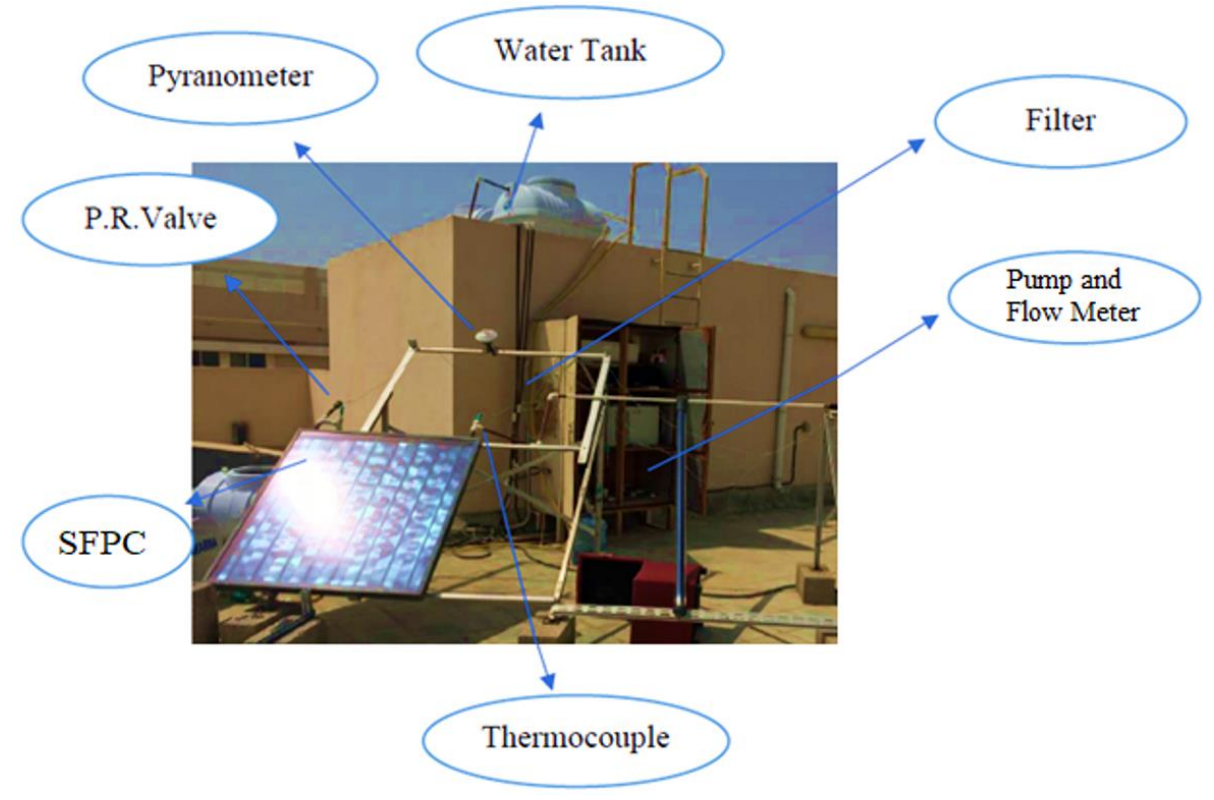

Figure 3 - Experimental setup on the roof

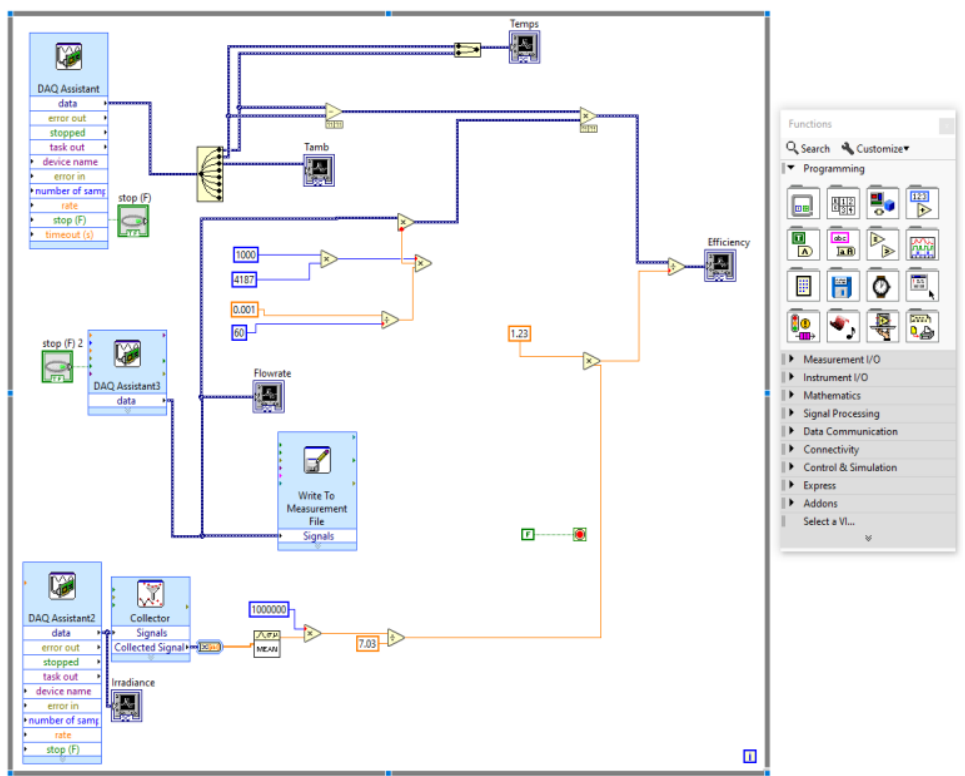

Figure 4 - Block diagram code made using LabVIEW 2019 to log experimental readings 


\section{Test conditions and results}

Test conditions,

- $\quad$ Time $=15$ minutes (one reading taken every 3 seconds, i.e. 300 readings taken)

- $\quad$ Fluid medium $=$ Water

- Mass flow rate $(\mathrm{m})=0.04 \mathrm{~kg} / \mathrm{s}$

- $\quad$ Specific heat capacity $(\mathrm{Cp})=4187 \mathrm{~kJ} / \mathrm{kg} \mathrm{K}$

- $\quad$ Area of collector $(\mathrm{A})=1.5 \mathrm{~m}^{2}$

- Average solar irradiance $(\mathrm{I})=1325.5 \mathrm{~W} / \mathrm{m}^{2}$

- Average ambient temperature $(\mathrm{Ta})=30.3^{\circ} \mathrm{C}$

- Average inlet temperature $(\mathrm{Ti})=28.3^{\circ} \mathrm{C}$

- Average outlet temperature $(\mathrm{To})=33.65^{\circ} \mathrm{C}$

- Maximum efficiency $(\eta)=0.4515(45.15 \%)$

The results represented in Figure 6 is the efficiency curve of the solar collector which is plotted by plotting the efficiency against the temperature difference between the ambient temperature $\left(\mathrm{T}_{\mathrm{a}}\right)$ and inlet temperature of fluid $\left(\mathrm{T}_{\mathrm{i}}\right)$ divided by the total solar irradiance (I), i.e. [ $\Delta \mathrm{T} / \mathrm{I}$ ]. The experimental data obtained is linearized for analysis and comparison.

\section{Simulation of SFPC using water}

Based on the theoretical equations discussed in 0 , a mathematical model made using MATLAB [6] is used to simulate the performance of a SFPC. The flow chart presenting the algorithm of the mathematical model is shown in Figure 5. From the results of the simulation as shown in Figure 6, it can be observed that a maximum efficiency of $0.5421(54.21 \%)$ is obtained for the same test conditions and collector dimensions as the experiment.

The experimental error can be calculated by the following equation,

Error $\%=\left|\frac{\text { Theoretical-Experimental }}{\text { Theoretical }}\right| \times 100 \%$

Table 1- Comparison of experimental and simulation efficiency values of the SFPC

\begin{tabular}{|l|l|c|}
\hline Method & Maximum Efficiency (\%) & Error (\%) \\
\hline Simulation (Theory) & $0.5421(54.21 \%)$ & \multirow{2}{*}{$16.8 \%$} \\
\hline Experiment & $0.4515(45.15 \%)$ & \\
\hline
\end{tabular}

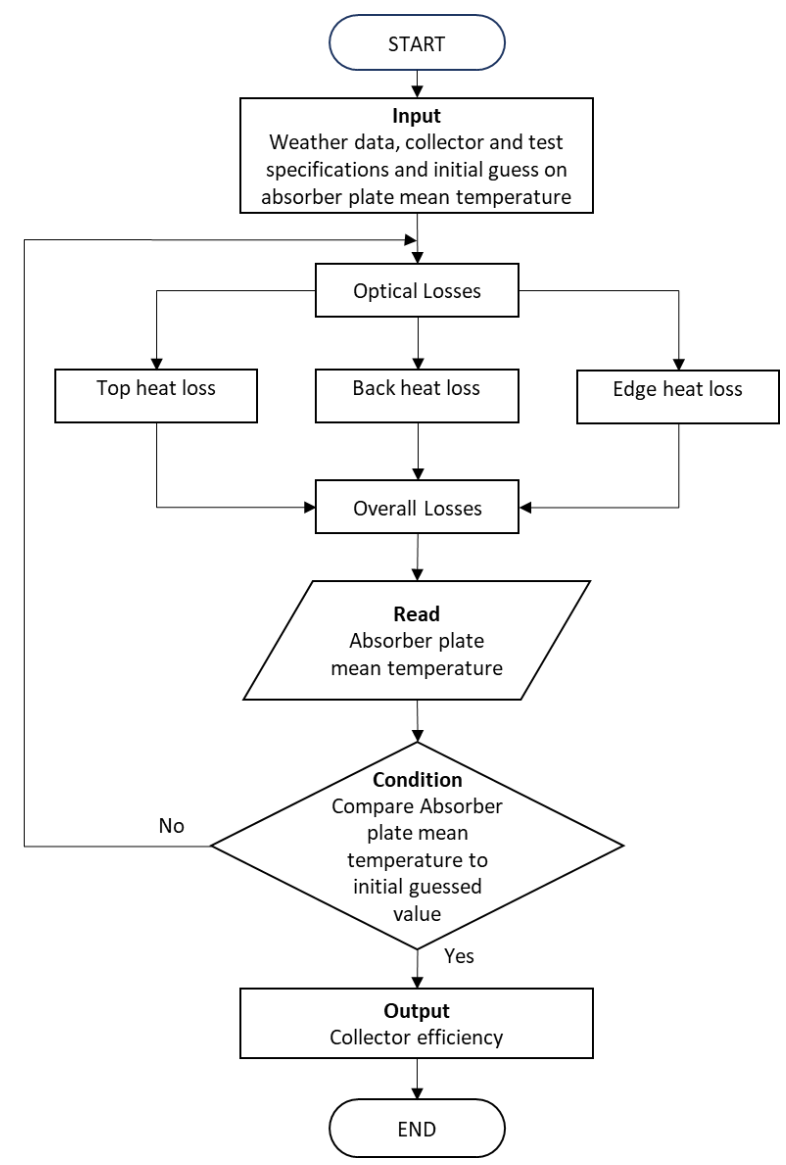

Figure 5 - Flow chart to demonstrate the algorithm of the MATLAB simulation

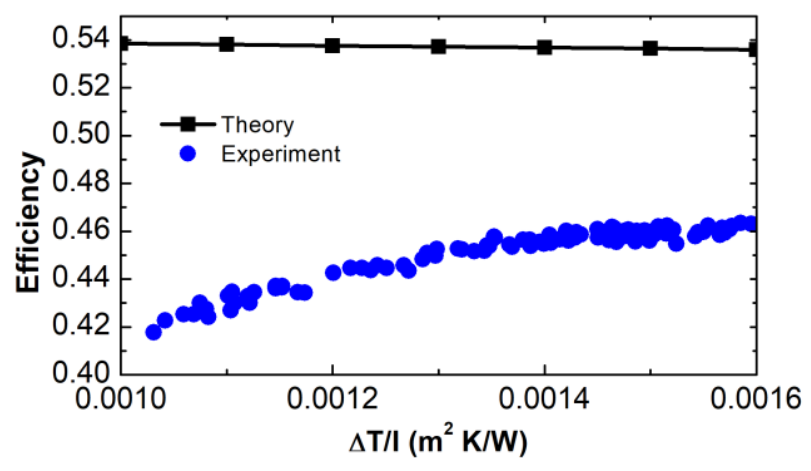

Figure 6 - Experimental vs. Simulation efficiency curve

Figure 6 represents the experimental and simulated efficiency curves are compared for the same range of $\Delta \mathrm{T} / \mathrm{I}$ and an error of $16 \%$ - 18\% can be observed which could occur due instrumental error or weather conditions like moving clouds and wind speeds.

\section{Nanofluid preparation and stability}

A nanofluid is a colloidal solution of nano sized particles suspended in a fluid. They are mainly used in heat transfer applications to increase the thermal conductivity of an existing fluid therefore improving the heat transfer to the system for an improved performance. Supplementary document shows the commonly used nanoparticles and base fluids used to make a nanofluid. $\mathrm{Al}_{2} \mathrm{O}_{3}$-Water nanofluids are commonly used nanofluids for heat transfer applications and many researchers have utilized it for their studies since they are very economical, abundant, have 
high thermal conductivity ( $38 \mathrm{~W} / \mathrm{m} \mathrm{K}$ ) and provide stable solutions on its own. Hence, $\mathrm{Al}_{2} \mathrm{O}_{3}$-Water is selected for this analysis.

There are two commonly used methods to synthesize nanofluids [9],

\section{One step method:}

The nanofluid is prepared by simultaneous preparation and dispersion of the nanoparticles. This is done by various methods like physical vapor condensation. The advantage is less agglomeration and sedimentation of nanoparticles i.e. stable solution and easy to prepare. The disadvantage is that it is expensive to prepare in large quantities

\section{Two step method:}

Nanoparticles are prepared separately and then the nanoparticle is stirred into the fluid medium with the help of intensive magnetic force agitation, ultrasonic agitation, high shear mixing, homogenizing or ball milling [9]. The advantage is that it is economical to prepare in large quantities. The disadvantage is agglomeration and sedimentation of nanoparticles i.e. low stable mixtures, hence reducing thermal conductivity.

The two-step method is commonly used to synthesize nanofluids [9]. But due to high surface area of the nanoparticles in the base fluid, the nanoparticles aggregate in the nanofluid or settle down causing instability in the mixture which reduces thermal conductivity and affects the performance of the SFPC. Hence, surfactants are usually used to stabilize the solutions. Adding surfactants are the best way to increase the stability of a nanofluid by reducing agglomeration of nanoparticles by providing an even distribution. But recent studies have shown that using surfactants for high temperature applications is not a great idea since the solution can foam up during the heating and cooling process [9] causing reduction in thermal conductivity and hence effecting the overall performance of the SFPC.

There are other methods to achieve a stable nanofluids like using ultrasonic agitation. In this method the fluid is stirred by using sound energy at ultrasonic frequencies (above 20 $\mathrm{kHz}$ ). This high frequency which is not audible to the human ear can break down the particles in the solutions and disperse them evenly creating a stable solution. R. Sadeghi et al. [10] investigated the ultrasonication effect on $\mathrm{Al}_{2} \mathrm{O}_{3}$ Water nanofluids for $1 \%, 2 \%, 3 \%$ volume concentration at temperatures of $15,25,35,45{ }^{\circ} \mathrm{C}$ for an ultrasonic frequency of $24 \mathrm{kHz}$ and ultrasonic power of 200 Watts. The ultrasonication was tested for periods of $30 \mathrm{~min}, 60$ min, $90 \mathrm{~min}, 120 \mathrm{~min}, 150 \mathrm{~min}$ and $180 \mathrm{~min}$ [10].

The optimum sonication time was found to be $150 \mathrm{~min}$ which provided a zeta potential of $50 \mathrm{mV}$ without using surfactants which is a good stability criterion as presented in Figure 7. Zeta potential is a common test conducted for measuring fluid stability by measuring the potential difference (in $\mathrm{mV}$ ) between the bulk of the fluid and surface of the solid particles in the solution. This optimum sonication time of 150 min gave the lowest nanoclustering size of $200 \mathrm{~nm}$ from an initial nanocluster size of $600 \mathrm{~nm}$. Lower the nanoclustering or agglomeration of the nanoparticles the more dispersion of particles, giving a more stable mixture. This can be visualized from the TEM images presented in Figure 7 which shows the different dispersion of nanoparticles in the nanofluid for different ultrasonication periods. Hence, residing to ultrasonic agitation to stabilize $\mathrm{Al}_{2} \mathrm{O}_{3}$-Water nanofluids over adding surfactants which adds extra costs and adds a risk of reducing stability resulting in low performance of the SFPC would be ideal.
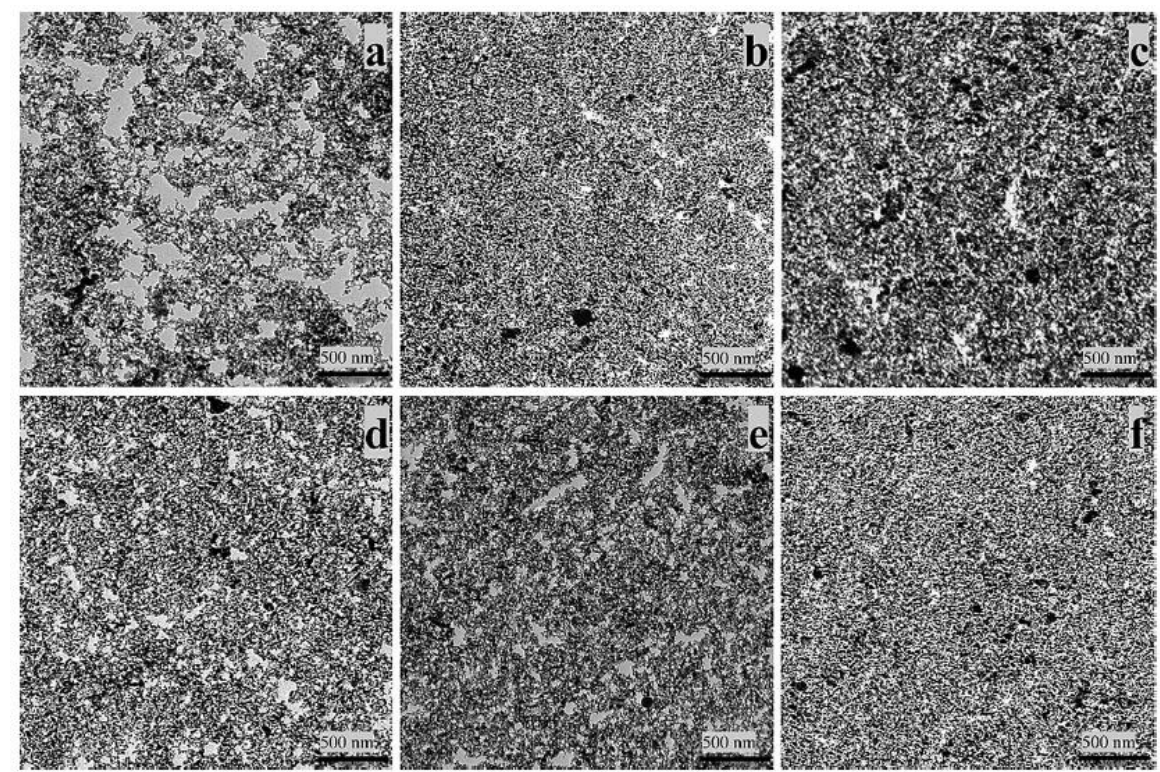

Figure $7-\mathrm{Al}_{2} \mathrm{O}_{3}$-Water nanofluid microstructure captured by TEM after sonicating for a) $30 \mathrm{~min}$, b) $60 \mathrm{~min}$, c) $90 \mathrm{~min}$, d) $120 \mathrm{~min}, \mathrm{e}) 150 \mathrm{~min}$ and f) $180 \mathrm{~min}[12]$ 
Table 2 - Zeta potential and associated solution stability [11]

\begin{tabular}{|c|c|}
\hline $\begin{array}{c}\text { Zeta Potential } \\
( \pm \mathrm{mV})\end{array}$ & Stability \\
\hline 0 & Little or no stability \\
\hline 15 & Some stability but settling lightly \\
\hline 30 & Moderate stability \\
\hline 45 & Good stability, possible settling \\
\hline 60 & $\begin{array}{r}\text { Very good stability, little settling } \\
\text { likely }\end{array}$ \\
\hline
\end{tabular}

\section{Nanofluid properties}

Nanofluid properties vary a lot from a normal fluid property due to the presences of nanoparticles in them. The number of nanoparticles present in the nanofluid mixture with respect to base fluid is denoted by ' $\varphi$ ' is volume concentration or volume fraction (\%), ' $d_{p}{ }^{\prime}$ is the diameter of nanoparticle in nanometers $(\mathrm{nm})$ and ' $\mathrm{T}$ ' is the temperature of nanofluid $\left({ }^{\circ} \mathrm{C}\right)$. Density of nanofluid can be expressed as single general equation which has been consistent with experimental data [13],

$\rho_{\mathrm{nf}}=\rho_{\mathrm{f}}(1-\varphi)+\rho_{\mathrm{p}} \varphi$

Here the subscripts ' $n f$ ' represents nanofluid, ' $f$ ' represents fluid (base fluid), and ' $p$ ' represents particle (nanoparticle) respectively. The tables in the supplementary document present the empirical and theoretically derived models for nanofluid properties (specific heat capacity, thermal conductivity, and viscosity) that are applicable for $\mathrm{Al}_{2} \mathrm{O}_{3}$ Water nanofluids for a range of volume concentrations, particle diameters and temperatures.

\section{Effect of volume concentration}

Plotting the expressions for every thermal conductivity and viscosity model for a range of volume concentrations as represented in Figure 8 and Figure 9, it can be observed that as the volume concentration increases, the thermal conductivity and viscosity of the nanofluid also increases.

Hence, the thermal conductivity and viscosity of a nanofluid is proportional its volume concentration.

$\mathrm{k}_{\mathrm{nf}}, \mu_{\mathrm{nf}} \propto \varphi$

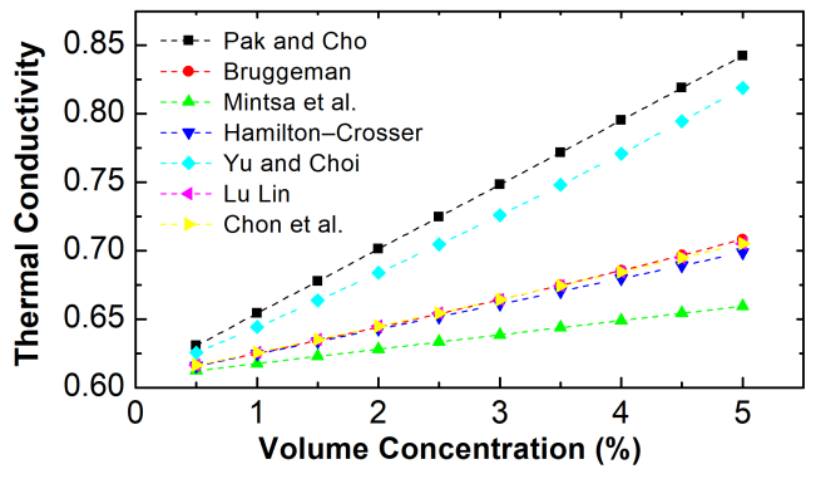

Figure 8 - Thermal conductivity of nanofluid vs. volume concentration for various models

From Figure 8 it can be observed that the Pak and Cho [14] model gives the maximum values of thermal conductivity and can be trusted since it has been empirically derived. Hence it is a selected model for the simulation.

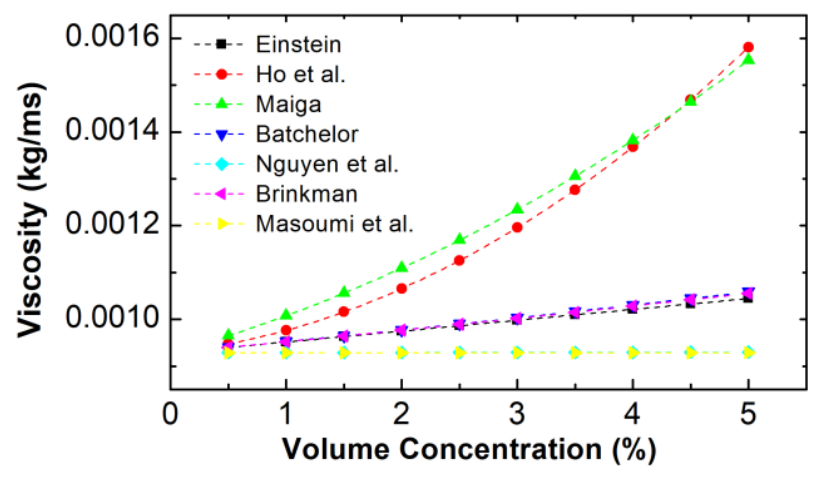

Figure 9 - Viscosity of nanofluid vs. volume concentration for various models

From Figure 9 it can be observed that the Ho et al. [15] model gives the maximum values of viscosity and can be trusted since it has been empirically derived. Hence it is a selected model for further analysis.

\section{Effect of particle diameter}

The Chon et al. [16] model for thermal conductivity of a nanofluid and the Masoumi et al. [17] model for the viscosity of a nanofluid take account of particle diameter $\left(d_{p}\right)$ in their expression. Hence, these models have been plotted for a varying volume concentration as shown in Figure 10 and Figure 11. It can be observed that for an increasing particle diameter, the thermal conductivity and viscosity of the nanofluid decreases, i.e. inversely proportional to particle diameter

$\mathrm{k}_{\mathrm{nf}}, \mu_{\mathrm{nf}} \propto \frac{1}{\mathrm{~d}_{\mathrm{p}}}$

But these variations are small and hence the effect of particle diameter can be considered marginal on the nanofluid properties in agreement to other studies [18].

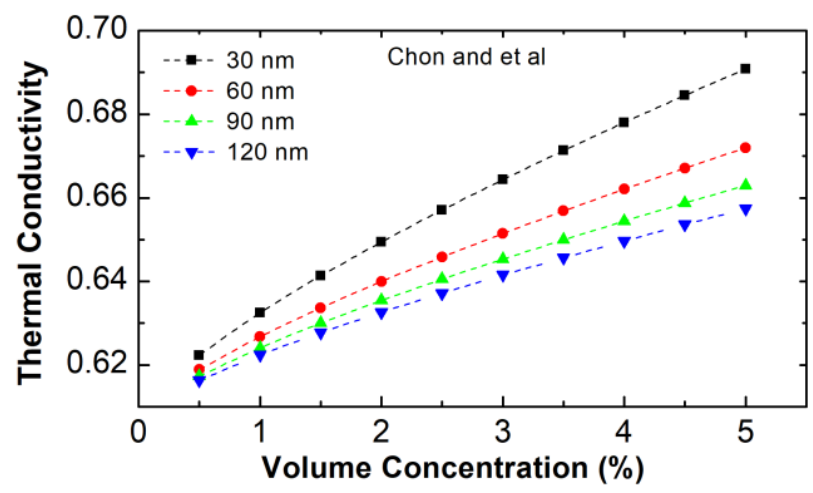

Figure 10 - Thermal conductivity vs. volume concentration for different particle diameters using the Chon et al. [16] model 
Nanofluids for Solar Thermal Collection

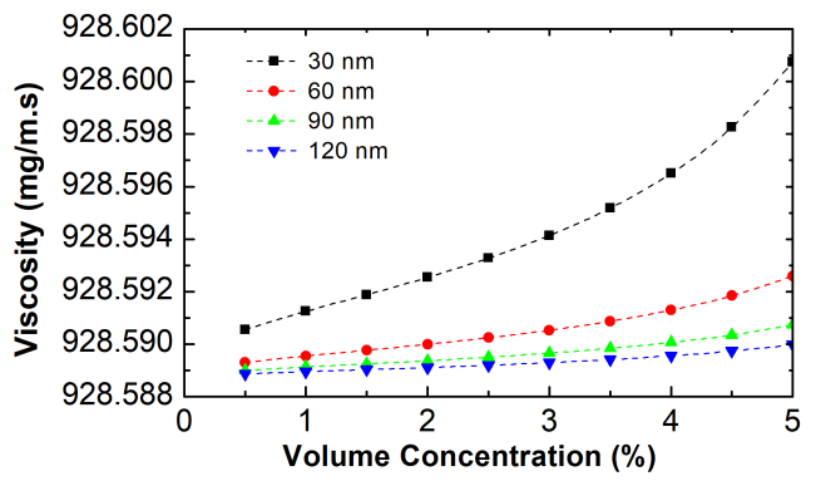

Figure 11 - Viscosity of nanofluid vs. volume concentration for different particle diameters using the Masoumi et al. [17] model

\section{Simulation of SFPC using Al2O3-Water nanofluid}

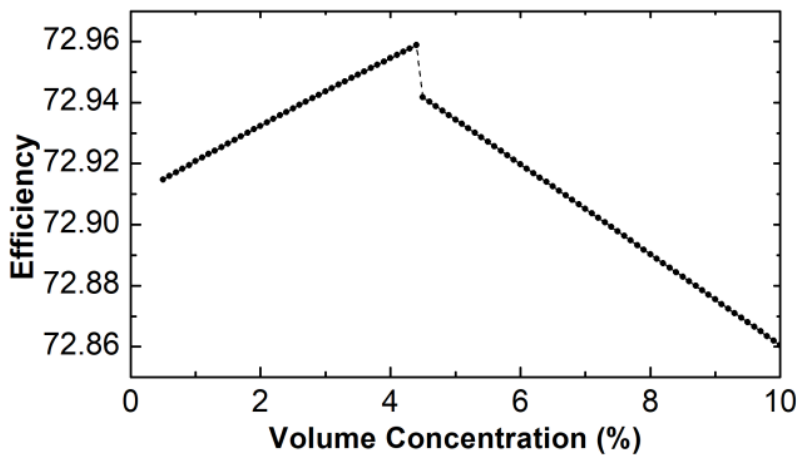

Figure 12 - Efficiency of SFPC vs. volume concentration of nanofluid

The simulation was modified by replacing the fluid properties with nanofluid properties from the selected models as discussed in 0 . The general equation of density was used followed by the Sekhar and Sharma [19] model $(\varphi<4 \%)$ and Xuan and Roetzel [20] model $(\varphi>4 \%)$ for specific heat capacity, Pak and Cho [14] model for thermal conductivity and Ho et al. [15] model for viscosity. In Figure 12, the efficiency of the SFPC was plotted for increasing volume concentrations for stagnation conditions at a constant temperature of the $\mathrm{Al}_{2} \mathrm{O}_{3}$-Water nanofluid. The optimum efficiency can be observed at a volume concentration of $4 \%$.

\section{Test conditions and results}

Test conditions,

- $\quad$ Solar irradiance $(\mathrm{I})=1000 \mathrm{~W} / \mathrm{m}^{2}$

- Mass flow rate $(\mathrm{m})=0.07877 \mathrm{~kg} / \mathrm{s}$

- Area of collector $(\mathrm{A})=3 \mathrm{~m}^{2}$

For the optimum volume concentration of $4 \%$ the simulation was tested at the given conditions, and the results can be observed in Table 3. An increase of $7.78 \%$ in efficiency of the SFPC was observed for using $\mathrm{Al}_{2} \mathrm{O}_{3}-$
Abdullah and et al

Water nanofluids over water. The efficiency curves are as depicted in Figure 13 and Figure 14.

Table 3 - Maximum efficiency achieved for nanofluids and water from the simulation at the same test conditions

\begin{tabular}{|l|l|}
\hline Fluid Medium & $\begin{array}{l}\text { Maximum Efficiency (\%) of } \\
\text { SFPC }\end{array}$ \\
\hline Water & $0.654(65.4 \%)$ \\
\hline $\begin{array}{l}\mathrm{Al}_{2} \mathrm{O}_{3} \text {-Water } \\
4 \%)\end{array} \quad(\varphi=$ & $0.7318(73.18 \%)$ \\
\hline
\end{tabular}

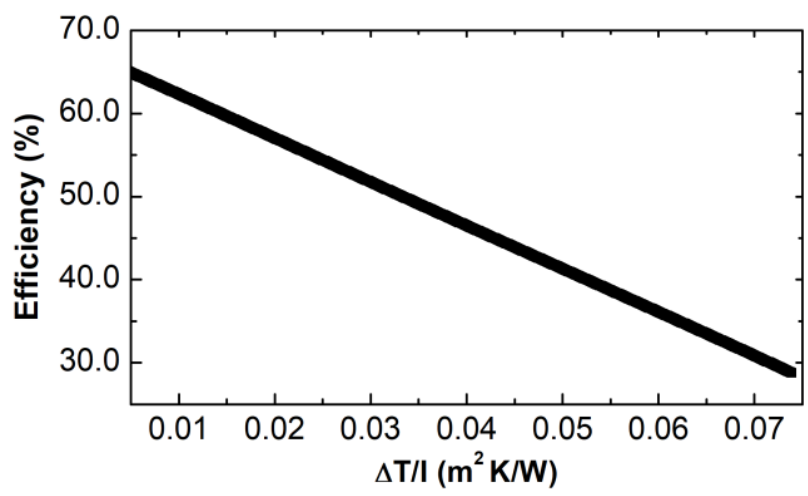

Figure 13 - Efficiency curve using water

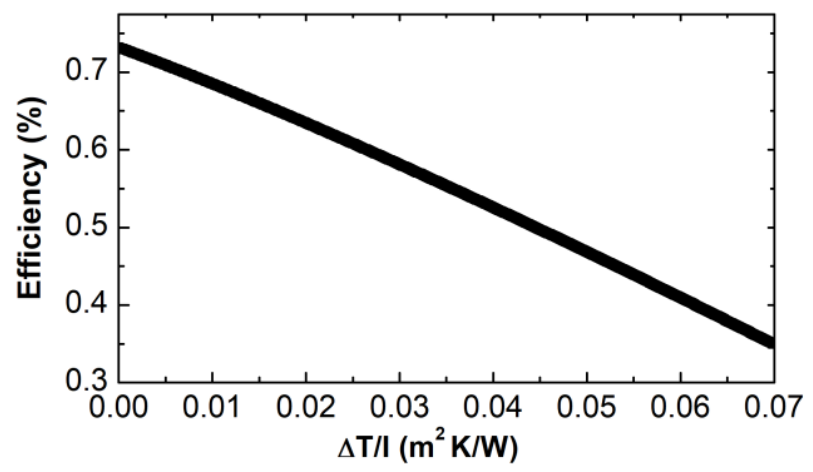

Figure 14 - Efficiency curve using $\mathrm{Al}_{2} \mathrm{O}_{3}$-Water nanofluid

\section{Reduction in area of SFPC after using nanofluids}

The size of a solar flat plate collector is a major disadvantage to the system. They are large and take up plenty of space which makes it difficult to set up, especially on the roofs. Since the efficiency of the SFPC has proven to increase by using nanofluids over conventional fluids like water, the size of the SFPC can be reduced significantly which is convenient and economical. The area of the collector $\left(A_{c}\right)$ is a factor on the efficiency of the collector (Equation 7), hence a reduction in the size of a SFPC can be observed by comparing the performances of using nanofluids and water.

$\eta=\frac{Q_{u}}{A_{c} I}=\frac{\dot{m} c_{p}\left(T_{o}-T_{i}\right)}{A_{c} I}$

From the simulation results discussed in 0 ,

Maximum efficiency for a $3 \mathrm{~m}^{2}$ collector using Water = $0.654(65.4 \%)$ 
Nanofluids for Solar Thermal Collection

Maximum efficiency for a $3 \mathrm{~m}^{2}$ collector using $\mathrm{Al}_{2} \mathrm{O}_{3}$ Water nanofluid $=0.7318(73.18 \%)$

Hence, Maximum efficiency for a $2.685 \mathrm{~m}^{2}$ collector with $\mathrm{Al}_{2} \mathrm{O}_{3}$-Water nanofluid $=0.654(65.4 \%)$

$$
1-\frac{2.685}{3}=10.5 \% \text { Reduction }
$$

Hence, there is a $10.5 \%$ reduction in area of a SFPC by using $\mathrm{Al}_{2} \mathrm{O}_{3}$-Water nanofluid over water

Figure 15 shows the reduction in the area of a SFPC by using different nanofluids [21].

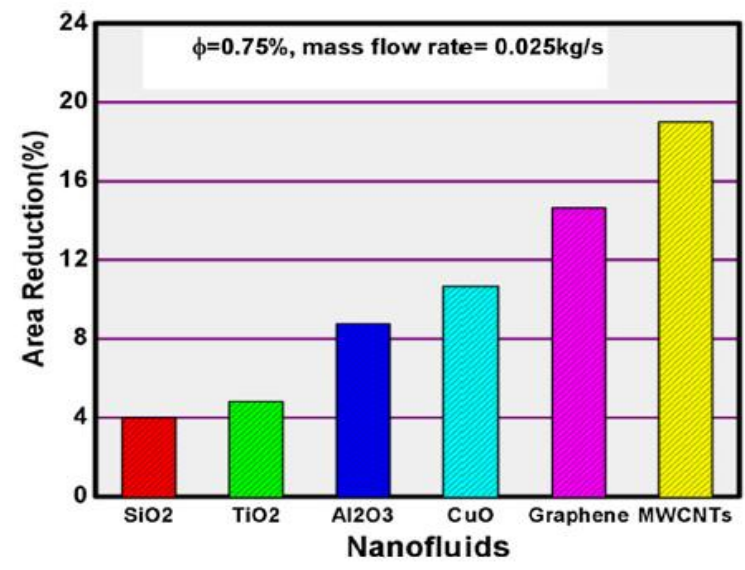

Figure 15 - Reduction in area of SFPC for different nanofluids [21]
Abdullah and et al

\section{Recommendations for Future Work}

Some of the suggested future improvements are mentioned in this section. Experiment and CFD simulation of using nanofluids in a SFPC. Study different empirical and theoretical models of nanofluids made by using different nanoparticles (MWCNTs, $\mathrm{CuO}$ etc..) and different base fluids (Ethelene glycol, Oil etc.). Investigate the payback period of using nanofluids in a SFPC over conventional fluids like water. Study the effect of using a magnetic field for nanofluid stability enhancement. Investigate the increase in pumping power in SFPC systems that use nanofluids.

\section{Conclusions}

Experiment are conducted on the performance of a SFPC using water, and the mathematical models using MATLAB simulation are validated. Nanofluid properties (density, specific heat capacity, thermal conductivity, and viscosity) were investigated for different models of $\mathrm{Al}_{2} \mathrm{O}_{3}$-Water based nanofluids. Effect of nanoparticle diameter on the properties of nanofluid was found to be marginal. Volume concentration of $\varphi=4 \%$ was found to be optimum giving the highest efficiency in the SFPC. The selected nanofluid properties were used to modify the simulation and an efficiency increase of $7.78 \%$ was observed by using $\mathrm{Al}_{2} \mathrm{O}_{3}$ Water nanofluid over water. Area of solar collector was reduced by $10.5 \%$ using $\mathrm{Al}_{2} \mathrm{O}_{3}$-Water nanofluid.

\section{Nomenclature}

\begin{tabular}{|c|l|c|}
\hline Symbol & Definition & Unit \\
\hline $\mathrm{A}_{\mathrm{c}}$ & Collector area & $\mathrm{m}^{2}$ \\
\hline $\mathrm{F}_{\mathrm{R}}$ & Collector heat removal factor & - \\
\hline $\mathrm{I}$ & Intensity of solar radiation & $\mathrm{W} / \mathrm{m}^{2}$ \\
\hline $\mathrm{T}_{\mathrm{c}}$ & Collector average temperature & ${ }^{\circ} \mathrm{C}$ \\
\hline $\mathrm{T}_{\mathrm{i}}$ & Inlet fluid temperature & ${ }^{\circ} \mathrm{C}$ \\
\hline $\mathrm{T}_{\mathrm{a}}$ & Ambient temperature & ${ }^{\circ} \mathrm{C}$ \\
\hline $\mathrm{U}_{\mathrm{L}}$ & Collector overall heat loss coefficient & $\mathrm{W} / \mathrm{m}^{2}$ \\
\hline $\mathrm{Q}_{\mathrm{i}}$ & Collector heat input & $\mathrm{W}$ \\
\hline $\mathrm{Q}_{\mathrm{u}}$ & Useful energy gain & $\mathrm{W}$ \\
\hline $\mathrm{Q}_{\mathrm{o}}$ & Heat loss & $\mathrm{W}$ \\
\hline$\eta$ & Collector efficiency & - \\
\hline$\tau$ & Transmission coefficient of glazing & - \\
\hline$\alpha$ & Absorption coefficient of plate & - \\
\hline$\dot{\mathrm{m}}$ & Mass flow rate & $\mathrm{kg} / \mathrm{s}$ \\
\hline$\varphi$ & Volume concentration or Volume fraction & $\%$ \\
\hline $\mathrm{d}$ & Diameter & $\mathrm{m}$ \\
\hline $\mathrm{T}$ & Temperature & $\mathrm{K} /{ }^{\circ} \mathrm{C}$ \\
\hline
\end{tabular}


Nanofluids for Solar Thermal Collection

Abdullah and et al

\begin{tabular}{|c|l|c|}
\hline $\mathrm{h}$ & Convective heat transfer coefficient & $\mathrm{W} / \mathrm{m}^{2} \mathrm{~K}$ \\
\hline $\mathrm{Q}$ & Heat transfer rate & $\mathrm{W} / \mathrm{m}^{2}$ \\
\hline $\mathrm{U}$ & Overall heat transfer coefficient & $\mathrm{W} / \mathrm{m}^{2} \mathrm{~K}$ \\
\hline $\mathrm{A}_{\mathrm{S}}$ & Surface area & $\mathrm{m}{ }^{2}$ \\
\hline$\Delta \mathrm{T}$ & Temperature difference & $\mathrm{K} /{ }^{\circ} \mathrm{C}$ \\
\hline$\rho$ & Density & $\mathrm{kg} / \mathrm{m}^{3}$ \\
\hline $\mathrm{c}_{\mathrm{p}}$ & Specific heat capacity & $\mathrm{J} / \mathrm{kg} \mathrm{K}$ \\
\hline$\mu$ & Viscosity & $\mathrm{kg} / \mathrm{m} \mathrm{s}$ \\
\hline $\mathrm{k}$ & Thermal conductivity & $\mathrm{W} / \mathrm{m} \mathrm{K}$ \\
\hline$\varphi_{\mathrm{m}}$ & Mass concentration or Mass fraction & $\mathrm{Wt} . \%$ \\
\hline Element & Definition & $\mathrm{Unit}$ \\
\hline $\mathrm{CO}{ }_{2}$ & Carbon dioxide & - \\
\hline $\mathrm{Al}_{2} \mathrm{O}_{3}$ & Aluminum oxide & - \\
\hline $\mathrm{ZnO}$ & Zinc oxide & - \\
\hline $\mathrm{CuO}$ & Copper oxide & - \\
\hline $\mathrm{MWCNTs}$ & Multi-walled carbon nanotubes & - \\
\hline Subscript & Definition & $\mathrm{Unit}$ \\
\hline $\mathrm{nf}$ & Nanofluid & - \\
\hline $\mathrm{f}$ & Fluid (Base fluid) & - \\
\hline $\mathrm{p}$ & Particle (nanoparticle) & - \\
\hline
\end{tabular}

\section{References}

[1] E. Babu, S. Yesudasan, and S. Chacko, "Cymatics Inspired Self-Cleaning Mechanism for Solar Panels," 2020.

[2] S. Yesudasan and S. Chacko, "Fast Local Pressure Estimation for Two Dimensional Systems From Molecular Dynamics Simulations," in ASME Power Conference, 2018, vol. 51401, p. V002T10A004.

[3] S. Yesudasan, R. Averett, and S. Chacko, "Machine Learned Coarse Grain Water Models for Evaporation Studies," Preprints, 2020.

[4] B. Noronha, S. Yesudasan, and S. Chacko, "Static and Dynamic Analysis of Automotive Leaf Spring: A Comparative Study of Various Materials Using ANSYS."

[5] V. Hotchandani, B. Mathew, S. Yesudasan, and S. Chacko, "Thermo-hydraulic characteristics of novel MEMS heat sink," Microsyst. Technol., pp. 1-13, 2020.

[6] T. Tsirakoglou and T. Tsirakoglou, "Numerical Simulation of a flat plate collector Numerical Simulation of a flat plate collector," no. September, 2011.

[7] S. U. S. Choi, "Enhancing thermal conductivity of fluids with nanoparticles," Am. Soc. Mech. Eng. Fluids Eng. Div. Publ. FED, vol. 231, pp. 99-105, 1995.

[8] A. Klevinskis and V. Bučinskas, "Analysis of a Flat-Plate Solar Collector / Plokščiojo Saulès Kolektoriaus Tyrimas," Moksl. - Liet. Ateitis, vol. 3, no. 6, pp. 39-43, 2012, doi: 10.3846/mla.2011.108.

[9] W. Yu and H. Xie, "A Review on Nanofluids: Preparation, Stability Mechanisms, and Applications," J. Nanomater., vol. 2012, p. 435873, 2012, doi: 10.1155/2012/435873.

[10] R. Sadeghi, S. G. Etemad, E. Keshavarzi, and M. Haghshenasfard, "Investigation of alumina nanofluid stability by UVvis spectrum," Microfluid. Nanofluidics, vol. 18, no. 5-6, pp. 1023-1030, 2015, doi: 10.1007/s10404-014-1491-y.

[11] R. Choudhary, D. Khurana, A. Kumar, and S. Subudhi, "Stability analysis of Al2O3/water nanofluids," J. Exp. Nanosci., vol. 8080, no. February, pp. 1-12, 2017, doi: 10.1080/17458080.2017.1285445. 
Nanofluids for Solar Thermal Collection

Abdullah and et al

[12] I. M. Mahbubul et al., "Effect of ultrasonication duration on colloidal structure and viscosity of alumina-water nanofluid," Ind. Eng. Chem. Res., vol. 53, no. 16, pp. 6677-6684, 2014, doi: 10.1021/ie500705j.

[13] S. Akilu, K. V. Sharma, A. T. Baheta, and R. Mamat, "A review of thermophysical properties of water based composite nanofluids,” Renew. Sustain. Energy Rev., vol. 66, pp. 654-678, 2016, doi: 10.1016/j.rser.2016.08.036.

[14] Young. I. C. Bock Choon Pak, "Hydrodynamic and Heat Transfer Study of Dispersed Fluids With Submicron Metallic Oxide," Exp. Heat Transf. J. Therm. Energy Transp. Storage Convers., no. January 2013, pp. 37-41, 2013.

[15] C. J. Ho, W. K. Liu, Y. S. Chang, and C. C. Lin, "Natural convection heat transfer of alumina-water nanofluid in vertical square enclosures: An experimental study," Int. J. Therm. Sci., vol. 49, no. 8, pp. 1345-1353, Aug. 2010, doi: 10.1016/j.ijthermalsci.2010.02.013.

[16] C. H. Chon, K. D. Kihm, S. P. Lee, and S. U. S. Choi, "Empirical correlation finding the role of temperature and particle size for nanofluid (Al2O3) thermal conductivity enhancement," Appl. Phys. Lett., vol. 87, no. 15, p. 153107, Oct. 2005, doi: 10.1063/1.2093936.

[17] N. Masoumi, N. Sohrabi, and A. Behzadmehr, "A new model for calculating the effective viscosity of nanofluids," $J$. Phys. Appl. Phys., vol. 42, no. 5, p. 055501, Mar. 2009, doi: 10.1088/0022-3727/42/5/055501.

[18] N. K. C. Sint, I. A. Choudhury, H. H. Masjuki, and H. Aoyama, "Theoretical analysis to determine the efficiency of a $\mathrm{CuO}$-water nanofluid based-flat plate solar collector for domestic solar water heating system in Myanmar," Sol. Energy, vol. 155, pp. 608-619, 2017, doi: 10.1016/j.solener.2017.06.055.

[19] Y. R. Sekhar and K. V. Sharma, "Study of viscosity and specific heat capacity characteristics of water-based Al 2 O 3 nanofluids at low particle concentrations," J. Exp. Nanosci., vol. 10, no. 2, pp. 86-102, Jan. 2015, doi: 10.1080/17458080.2013.796595.

[20] Y. Xuan and W. Roetzel, "Conceptions for heat transfer correlation of nanofluids," Int. J. Heat Mass Transf., vol. 43, no. 19, pp. 3701-3707, Oct. 2000, doi: 10.1016/S0017-9310(99)00369-5.

[21] S. K. Verma, A. K. Tiwari, and D. S. Chauhan, "Experimental evaluation of flat plate solar collector using nanofluids," Energy Convers. Manag., vol. 134, pp. 103-115, 2017, doi: 10.1016/j.enconman.2016.12.037. 